\title{
The correlation between botanical source and the biologically active compounds of propolis
}

\author{
Ömür Gençay Çelemli* (D), Mehmet Atakay² (D), Kadriye Sorkun' (D) \\ 'Department of Biology, Hacettepe University Faculty of Science Beytepe 06800, Ankara, Turkey \\ 2Department of Chemistry, Hacettepe University Faculty of Science Beytepe 06800, Ankara, Turkey
}

ORCID IDs of the authors: Ö.G.C.. 0000-0002-2215-9552; M.A. 0000-0002-7102-2974; K.S. 0000-0003-3224-7748.

Cite this article as: Gençay Celemli Ö, Atakay M, Sorkun K (2019). The correlation between botanical source and the biologically active compounds of propolis. Istanbul J Pharm 49 (2): 81-87.

\begin{abstract}
In this research, five propolis samples collected from Turkey were investigated to observe the correlation between botanical sources and chemical contents of the samples and in this way emphasize the influence of botanical sources of propolis on its chemical characterization. As a first step, to determine the botanical sources of the samples, microscopic analysis was performed. According to the microscopic analysis results; two samples that were collected from Rize (P1 and P2), were characterized as most probably being chesnut propolis; while one sample collected from Tekirdağ (P3) was evaluated as being a mixed type, in the other Tekirdağ sample (P4), the pollens belonging to the taxa of the Brassicaceae family were found as dominant. The sample collected from Sivas (P5); was also recognized as mixed type. The second step of the research was the chemical analyses of the propolis samples. According to the results; the balsamic contents of the propolis samples ranged between 59.97 and $83.31 \%$, total phenolic contents were ranged between $27.56 \pm 0.05$ and $171.93 \pm 0.28 \mathrm{mgGAE} / \mathrm{g}$. The minimum flavone and flavonol content of $0.28 \pm 0.01 \%$ was found in the P1 sample described as chesnut propolis and colected from Rize. The maximum value $5.1 \pm 0.07 \%$ was found in the P4 sample as was total phenolic content. Flavanones and Dihydroflavonols contents varied between $6.58 \pm 0.009-12.94 \pm 0.007 \%$. According to the GC-MS results the investigated samples contained compounds belonging to the various groups. With regard to the Excel correllation, the balsamic content showed a negative correlation with total phenolic content, flavone and flavonol content, flavanones and dihydroflavonols content.
\end{abstract}

Keywords: Propolis, chestnut, microscopic, total phenolic, UV-Vis, GC-MS

\section{INTRODUCTION}

The increasing attention on natural products and alternative medicines has elevated the interest in bee products such as honey, royal jelly, pollen and propolis (Daleprane et al., 2013).

Propolis is a natural material that is collected by honeybees from the buds and exudates of trees and plants. It has been used in folk medicines in many regions of the world since ancient times (Jun, 2006). Honeybees enrich this material with their saliva and secretions and it is used in their hives for various purposes such as construction, adaptation, and protection (Daleprane et al. 2013).

The physically, propolis is a sticky, dark-colored material. Its colour varies from yellow-green to dark brown depending on its botanical source and its freshness. It is hard and fragile when it is taken from the refrigirator, but becomes soft and very sticky when it is at room temperature (Ghisalberti 1979). 
The major plant sources of propolis are poplar, birches, willows, chesnut, elms, pine trees, oaks, spruces and ashes (Bonvehi et al. 1994).

The chemical composition of propolis depends on the botanical source. However, despite the differantion of the botanical sources, propolis samples generally share many similarities in their overall composition, (Daleprane and Abdalla 2013). Generally, it is composed of 50\% resin, 30\% wax, $10 \%$ essential and aromatic oils, $5 \%$ pollen and $5 \%$ other substances, including organic remains (Burdock 1998). The chemical compounds in propolis resin (raw propolis) are sourced from: plant exudate collected by bees, from bee metabolism, and materials which are introduced during propolis elaboration (Marcucci 1995).

Propolis contains polyphenols, terpenoids, steroids and amino acids (Daleprane and Abdalla, 2013). Flavonoids are the major group identified in propolis extract and which are ever-present in the plant kingdom (Burdock 1998). The pharmacological and antioxidant activities of propolis may be caused by flavonoids (Bonvehi et al. 1994).

Owing to their geographical divergences, propolis samples from Europe, South America and Asia have different chemical compositions. While propolis from Europe and China contains mostly flavonoids and phenolic acid esters, the major components in Brazilian propolis are terpenoids and prenylated derivatives of p-coumaric acids (Kumazawa et al. 2004).

Propolis has therapeutic activities and may have uses in the pharmaceutical and food processing industries. It exhibits many biological activities; immunomodulatory, antibacterial, fungicidal, anti-inflammatory, healing, analgesic/anesthetic, and anticarcinogenic effects (Daleprane and Abdalla 2013). Although it has a wide range of biological activities, there are no standards for its extraction procedure or its composition (Cunha et al. 2004).

The efficiency of propolis in therapeutics is related with its collection conditions and other parameters like microscopical, chemical and microbiological. The broad variableness in the chemical content of propolis makes these controls more necessary (Woisky and Salatino 1998).

The quality of propolis is related with its chemical composition and botanical source. The botanical, geographical origin and climatic conditions mostly affect the phenollic contents of the propolis. So, the description and quantification of the phenolics of propolis are important for detecting its quality (Gomez-Carvaca et al. 2006).

In this research we determined botanical origin, the total phenolic content, flavone/flavonol and flavanones/dihydroflavonols contents of five propolis samples to reflect the correlation between the botanical source and chemical contents of the propolis. Also the samples were compared in terms of their volatile compound contents according to the GC-MS analysis results.

\section{MATERIALS AND METHODS}

\section{Sample collection}

Propolis samples were collected from Rize (Black Sea RegionEuropean-Siberian Phytogeographical Region-P1, P2), Tekirdağ (Thracian Region of Turkey- European-Siberian Phytogeographical Region-sample P3, P4), Sivas (East Anatolia RegionIrano-Turanian Phytogeographical Region-P5) in the fall season of 2016 (Table 1). The samples were collected from the edges of beehives with a spatula by local beekepers.

\section{Microscopic analysis of propolis samples}

For microscopic analysis the samples were prepared according to the method of Warakomska and Maciejewicz (1992) with some modifications.

The propolis samples were ground to a powder and this was added to the mixture of ethanol-chloroform-acetone (1:1:1) and vortexed. After this process, it was filtered and centrifuged at 3500-4000 rpm for $20 \mathrm{~min}$. Then, the supernatant was poured. The slides were prepared from the sediment using glycerin gelatin.

\section{Propolis extraction}

The extraction procedure was carried out following Popova et al. (2007).

\section{Balsamic content}

From each crude sample, three ethanolic extracts were prepared. Two $\mathrm{ml}$ of each extract were evaporated and the balsamic contents were calculated according to the weight of the dry residues (Popova et al. 2007).

\section{Estimation of total polyphenol content by the Folin-Cio- calteu Colorimetric Method}

The total polyphenol content of EEP was determined using the Folin-Ciocalteu colourimetric method (Slinkard and Singleton 1977). Gallic acid was used as standard compound and the results were given as $\mathrm{mg}$ gallic acid equivalents (GAE) in $\mathrm{g}^{-1}$ of propolis extract.

\section{Determination of flavone and flavonol content by UV- Vis Spectrophotometer}

Flavone and flavonol content were determined according to Popova et al (2007). Quercetin was used as a reference compound.

\section{Determination of flavanone and dihydroflavonol con-} tent by UV-Vis Spectrophotometer

$1 \mathrm{~mL}$ of the the ethanolic propolis extract and $2 \mathrm{~mL}$ of DNP (2,4-dinitrophenylhydrazine) were mixed and then diluted in

Table 1. Symbols, locations and collection dates of propolis samples

\begin{tabular}{|lcc|}
\hline Sample no & Location & Collection dates \\
\hline P1 & Rize & Fall-2016 \\
P2 & Rize & Fall-2016 \\
P3 & Tekirdağ & Fall-2016 \\
P4 & Tekirdağ & Fall-2016 \\
P5 & Sivas & Fall-2016 \\
\hline
\end{tabular}


Table 2. Pollen types recorded from the propolis samples and their frequency

Sample No

Plant family

Plant taxa

P1

P2

P3

P4

P5

Apiaceae

$\mathrm{R}$

$\mathrm{R}$

$\mathrm{R}$

$\mathrm{R}$

$\mathrm{S}$

Asteraceae

Centaurea spp.

$\mathrm{R}$

R

M

M

M

Helianthus annus

R

$\mathrm{R}$

Taraxacum spp.

Xanthium spp.

R

M

$\mathrm{R}$

R

Berberidaceae

Betulaceae

Carpinus spp.
Corylus spp.

R

R

M

Boraginaceae

Anchusa spp.

Echium spp.

Heliotropium spp.

Brassicaceae

Caryophyllaceae

Chenopodiaceae

cistaceae

Dipsecaeea

Scabiosa spp.

Ericaceae

Fabaceae

Lathyrus spp.

Lotus spp.

Medicago spp.

Onobrychis spp.

Trifolium spp.

Vicia spp.

Fagaceae

Castaneae sativa

Quercus spp.

$\mathrm{R}$

$\mathrm{R}$

$R$

R

R

$\mathrm{R}$

R

$\mathrm{R}$

$\mathrm{R}$

$\mathrm{R}$

D

M

R

S

$\mathrm{R}$

R

R

M

R

R

R

R

R

M

M

$\mathrm{R}$

$\mathrm{R}$

$\mathrm{R}$

M

$\mathrm{R}$

$\mathrm{R}$

M

R

R

R

M

R

R

$\mathrm{R}$

D

D

Geraniaceae

Lamiacaea

Thymus spp.

R

Teucrium spp.

Liliaceae

Pinaceae

Platanaceae

Poaceae

Plantaginacae

Rosaceae

Salicaceae

$$
\text { . }
$$

Platanus spp.

Plantago spp.

Populus spp.

R

Salix spp.

$\mathrm{R}$

R

Solanaceae

*Pollen types recorded from the propolis samples and their frequency (D: dominant: >=45\%, S: secondary: $16-44 \%, \mathrm{M}$ : $\operatorname{minor}$ : $3-15 \%$ : R: rare $<3 \%$.

$100 \mathrm{~mL}$ of methanol. The solution was heated at $50{ }^{\circ} \mathrm{C}$ for 50 min. The solution was diluted with $10 \% \mathrm{KOH} .10 \mathrm{~mL}$ methanol was added to the solution and again diluted to $25 \mathrm{~mL}$ with methanol. Naringenin was used as a reference compound.

\section{Chemical analysis of the propolis samples by GC-MS}

A GC 6890N instrument coupled with a mass detector (MS5973; Agilent) was used for analysis of the volatile compounds in the propolis samples. A DB 5MS column $(30 \mathrm{~m} \times 0.25 \mathrm{~mm}, 0.25$ 
Table 3. Balsamic contents $(\%)$ and concentration of polyphenols (total phenols, flavones and flavonols; flavanones and dihydroflavonols) in propolis extracts

\begin{tabular}{|lcccc|}
$\begin{array}{l}\text { Propolis } \\
\text { sample }\end{array}$ & $\begin{array}{c}\text { Balsamic } \\
\text { content }(\%)\end{array}$ & $\begin{array}{c}\text { Total phenolic content } \\
\text { (mgGAE/gEEP) }\end{array}$ & $\begin{array}{c}\text { Flavone and Flavonol } \\
\text { Content (\%) }\end{array}$ & $\begin{array}{c}\text { Flavanones and } \\
\text { Dihydroflavonols (\%) }\end{array}$ \\
\hline P1 & 59.97 & $36.36 \pm 0,14$ & $0.28 \pm 0.01$ & $9.21 \pm 0.01$ \\
P2 & 83.31 & $27.56 \pm 0.05$ & $0.31 \pm 0.01$ & $6.58 \pm 0.009$ \\
P3 & 29.15 & $144.03 \pm 0.32$ & $4.6 \pm 0.03$ & $10.54 \pm 0.005$ \\
P4 & 41.15 & $171.93 \pm 0.28$ & $5.1 \pm 0.07$ & $12.82 \pm 0.01$ \\
P5 & 70.47 & $28.7 \pm 0.14$ & $4.43 \pm 0.03$ & $12.94 \pm 0.007$ \\
\hline
\end{tabular}

Table 4. The identified compound groups from the propolis samples by GC-MS analysis

\begin{tabular}{|lccccc|} 
Compounds & P1 & P2 & P3 & P4 & P5 \\
\hline Alcohols & 9.45 & 11.27 & 3.64 & 9.49 & 6.42 \\
Aldehydes & 5.46 & 3.67 & 0.06 & 0.77 & 0.79 \\
Aliphatic acids and their esters & 2.03 & 3.04 & 2.38 & 7.89 & 8.69 \\
Carboxylic acids and their esters & 32.97 & 0.98 & 3.28 & 1.11 & - \\
Flavonoids & 8.66 & 5,78 & 34.87 & 32.38 & 47.03 \\
Hydrocarbons & 3.42 & 2.63 & - & 0.37 & 0.42 \\
Ketones & & 0.36 & 0.54 & - & - \\
Cinnamic acids and their esters & - & - & - & 5.76 & 3.51 \\
Terpenes & 2.62 & 0.16 & & 0.65 & 0.44 \\
\hline
\end{tabular}

$\mu \mathrm{m}$ film thickness) was used and Helium for the mobile phase. The compounds were identified in Wiley's NIST Mass Spectral Library (Gençay and Salih 2005).

\section{RESULTS}

\section{Microscopic analysis results}

According to the microscopic analysis results, the P1 and P2 samples were characterized as chesnut propolis, P3 as a mixed type containing Brassicaceae and Salix spp. pollens in remarkable ratios and these pollens were defined as secondary. The P4 sample contained pollen belonging to the Brassicaceae family in a dominant ratio (Table 2). The P5 sample could also be characterized as a mixed type.

The microscopic analysis results show the possible botanical sources of the propolis samples and also reflects the geographical source of the areas where the propolis was collected.

\section{Chemical analysis results}

The balsamic contents of the propolis samples varied between 29.15-83.31\% (Table 3). The maximum value belonged to the P2 sample collected from Rize and characterized as chesnut propolis.

The total phenolic contents of the samples ranged between $27.56 \pm 0.05$ and $171.93 \pm 0.28 \mathrm{mgGAE} / \mathrm{gEEP}$ (Table 3). The minimum value was found in the chesnut sample (P2) collected from Rize and the maximum value (171.93 $\pm 0.28 \mathrm{mgGAE} / \mathrm{gEEP})$ was found in the P4 sample that was mostly sourced from plants belonging to the Brassicaceae family.

The minimum flavone and flavonol content of $0.28 \pm 0.01 \%$ was found in the P1 sample described as chesnut propolis and col- ected from Rize. The maximum value $(5.1 \pm 0.07 \%)$ was found in P4 sample as was the total phenolic content (Table 3).

The flavanones and dihydroflavonols contents changed between $6.58 \pm 0.009-12.94 \pm 0.007 \%$ (Table 3). The minimum value was found in the P2 sample and the maximum value was found in the P5 sample.

According to the C-MS analysis results, the five propolis samples investigated contained compounds belonging to the alcohols, aldehydes, aliphatic acids and their esters, carboxylic acids and their esters, flavonoids, hydrocarbons, ketones, cinnamic acids and their esters, and terpens groups (Table 4).

With respect to the volatile compound analysis results it is appeared that the P5 sample had the highest flavonoid content (47.03\%) and was characterized as a mixed type propolis. The P3 and P4 samples also had considerably high flavonoid contents (34.87\%-32.38\%) with Brassicaceae pollen in secondary ratios. Moreover, the P1 and P2 samples characterized as chesnut propolis had a lower flavonoid content.

\section{DISCUSSION}

The determination of the plant taxa of pollen occuring in propolis samples, gives information about the vegetation surrounding the beehive and also the geographical region where the propolis was gathered (Barth 1998).

The research related with Turkish propolis is generally about its chemical characterization or usage areas. The number of investigations into propolis pollen analysis is very limited not just in Turkey but also in the world. Gençay (2004) investigated the botanical sources of Erzincan propolis located in the Irano- 
Turanian Phytogeographic Region. They found mostly the taxa belong to the Apiaceae, Asteraceae, Campanulaceae, Fabaceae, Fagaceae, Lamiaceae, Liliaceae, Pinaceae, Rhamnaceae, Rosaceae, Salicaeae, Scrophulariaceae families as souces of Erzincan propolis. They also found the Salix spp. pollen in their investigated propolis samples. We found Salix spp. pollen in four of the five samples (P1, P3, P4, P5) and of these, the Tekirdağ sample (P3) contained Salix spp. pollen in secondary ratios.

Çelemli and Sorkun (2012) determined the botanical choices made by honeybees when collecting propolis in Tekirdağ by microscopic analysis and the results show that plants which belonged to the Asteraceae, Boraginaceae, Brassicaceae, Fabaceae and Salicaceae families were the plants of choice. These results are similiar to our findings.

Also on a global level, the palynological research into propolis is very limited. Barth (1998), analysed Brazilian propolis samples according to their pollen contents and found Eucalyptus spp., Eupatorium spp. and Mimosa caesalpiniaefolia pollens with dominant ratios in some of the investigated samples.

The percentage balsamic content is extremely important for propolis because if the amount of balsam is high, the wax content will be low. A high balsam content causes a higher amount of biologically active components. Popova et al. (2007) investigated some poplar propolis. They found the minimum balsamic content value as 18\%, maximum value $82 \%$ and mean value $57 \%$.

We found the minimum balsamic content value in the P3 sample (29.15\%) and the maximum in the P2 sample (83.31\%). According to the Excel correllation; the balsamic content results had a negative correllation with total phenolic (mgGAE/ gEEP), Flavone and Flavonol , Flavanones and Dihydroflavonols contents.

Many compounds that are isolated from propolis as phenolics have important protective effects against oxidation reactions. Flavones, coumarines and other phenolics have a reducing activity, hydrogen donors and metal chelating properties.(Gülçin et al. 2010).

Bankova (2005) proposed that the total phenolics amounts are related with biological activity and are more informative that the quantification of individual components. It means that calculating the amounts of active compound groups is more effective than determining individual components.

As given in Table 3, the total phenolic compound of the investigated samples varies between $27.56 \pm 0.05$ and $171.93 \pm 0.28$ mgGAE/gEEP. According to our results the P1, P2, and P5 samples have lower total phenolic contents compared to the other two samples. The P1 and P2 samples were identified as chesnut propolis and P5 as a mixed type. The highest total phenolic content (171.93 $\pm 0.28 \mathrm{mgGAE} / \mathrm{gEEP})$ belonged to the P4 sample. Its possible botanical origin is observed as the taxa belonging to the Brassicaceae family and Salix spp. in particular.

Popova et al. (2005) studied the total Phenolic contents of some propolis from Turkey (Yozgat, İzmir, Kayseri, Adana, Er- zurum and Artvin). The Yozgat, İzmir ve Kayseri samples described as typical poplar samples displayed very similiar phenolic and flavonoid content. The Adana, Erzurum and Artvin samples were characterized by low phenolic and very low flavonoid concentrations. Total phenolic contents were found as $26.4 \%, 30.4 \%, 27.5 \%, 8.2 \%, 10.5 \%$ and $14.5 \%$ respectively. These results are lower than ours. In further research concerning Turkish propolis Gülçin et al., (2010) found the total phenolic content of lyophilized aqueous extract of propolis from the Erzurum province of Turkey to be $124.3 \mu \mathrm{g}$ (GAE)/g (LAEP).

Moreira et al. (2008) investigated the total phenolic content of one propolis type that contains $45 \%$ Castanea sativa pollen and found it to be $329 \mathrm{mgGAE} / \mathrm{g}$. Yet in our samples that contain Castane sativa pollen in dominant ratios, there was a lower

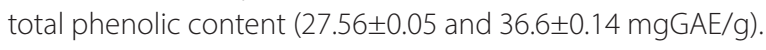

According to previous global research, the total phenolic contents of propolis from different countries can be summarized as: Argentina (187-212 $\pm 9.2 \mathrm{mg} / \mathrm{g})$, Australia (269 \pm 16.3 $\mathrm{mg} / \mathrm{g})$, Brazil (8.8-299 mg/g), Bulgaria (220 $\pm 2.5 \mathrm{mg} / \mathrm{g})$, Chile (210 $\pm 11.1 \mathrm{mg} / \mathrm{g})$, China (23.20-302 $\pm 4.3 \mathrm{mg} / \mathrm{g})$, Cyprus (85.7 $\pm 5.1-100.4 \pm 7.2 \mathrm{mgCAE} / \mathrm{g})$, Greece ( 146.2 $\pm 7.2-338.5 \pm 13.2$ $\mathrm{mgCAE} / \mathrm{g})$, Greek islands (80.2 $\pm 3.2-146.2 \pm 10.2 \mathrm{mgCAE} / \mathrm{g})$,

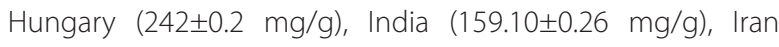
(3.08 and 36\%.), Korea (160.6 $\pm 2.4-307.2 \pm 5.3 \mathrm{mg} / \mathrm{g}$ ), New Zealand $(237 \pm 6 \mathrm{mg} / \mathrm{g})$, Portugal $(151 \pm 0.01-329 \mathrm{mg} / \mathrm{g})$, South Africa $(99.5 \pm 4.4 \mathrm{mg} / \mathrm{g})$, Taiwan $(210 \pm 20-335 \mathrm{mgCE} / \mathrm{g})$, Thailand $(31.2 \pm 0.7 \mathrm{mg} / \mathrm{g})$, Ukraine $(255 \pm 7.4 \mathrm{mg} / \mathrm{g})$, United States

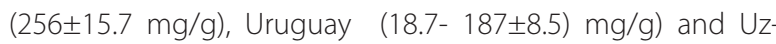
bekistan (174 $\pm 6.7 \mathrm{mg} / \mathrm{g}$ ) (Ahn et al. 2007, Bonvehi et al.1994, Chen et al. 2004, Choi et al. 2006, Choi et al. 2013, Cottica e al. 2011, Daleprane and Abdalla 2013, Kalogeropoulos et al. 2009, Kumazawa et al. 2004, Mohammadzadeh et al. 2007, Moreira et al. 2008, Popova et al. 2004, Woisky and Salatino 1998, Yaghoubi et al. 2007).

Popova et al (2007). analysed 114 poplar propolis samples and they found a minimum phenolic value of $4.6 \%$ and maximum $46 \%$ with a mean value of $28 \%$. They also they found an indicative negative correlation between the total phenolics and the MIC values.

Sarıkaya et al. (2009) found the total phenolic contents of two chesnut propolis samples to be $313 \pm 9.48 \mathrm{mg} / \mathrm{g}$ and $476 \pm 4.78 \mathrm{mg} / \mathrm{g}$. In comparison with these results, our total phenolic results are too low for chesnut propolis samples (P1, P2).

With regard to the Excel correlation, the total phenolic contents had a positive corellation with flavone and flavonol content, flavanones and dihydroflavonols contents.

Colorimetric analysis is used for quantitative identification of flavonoids in propolis. The aluminium chloride method is used to calculate the flavone and flavonol content in propolis (Caravaca et al. 2006).

With regard to the spectrophotometric results, the flavone and flavonol contents of the propolis samples varied between 
$0.28 \pm 0.0 .01$ and $5.1 \pm 0.07 \%$. The P4 sample shows the maximum content for flavone and flavonol content as matching total phenolic content. The P1 and P2 samples show similarity in their flavone and flavonol contents $(0.28 \pm 0.01,0.31 \pm 0.01 \%)$ as well as their total phenolic contents. Although the P5 sample had a lower total phenolic content compared to the P3 and

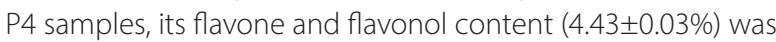
very similiar to the P3 and P4 samples.

Poplar-type propolis from numerous countries was analysed by Popova et al. (2007) and they found the minimum flavones and flavonols value to be $1.3 \%$ and the maxium value to be $17.9 \%$.

Popova et al. (2007) couldn't find any significant correlation between total flavones/flavonols and MIC values. Popova et al. (2005) studied flavone and flavonol contents of Yozgat, İzmir, Kayseri, Adana, Erzurum and Artvin samples. They found the values to be $8.7 \%, 9.6 \%, 5.6 \%, 1.5 \%, 2.0 \%$ and $2.0 \%$ respectively.

Trusheva et al., (2007) determined the total amounts of extracted total flavones and flavonols according to the different extraction methods. By maceration $72 \mathrm{~h}$ and with ratio of propolis solvent (1:20) and (1:10) were analysed and total flavones and flavonols were found as $8.6 \pm 0.1 \%$ and $8.8 \pm 0.1 \%$ respectively. By ultrasound extraction the value of total phenolics for 1:20 propolis/solvent 10 min was $9.4 \pm 0.2 \%, 1: 20$ propolis/solvent 30 min $9.4 \pm 0.2 \%$ and 1:20 propolis/solvent 30 min 8.6 $\pm 0.1 \%$. MAE (Microwave assayed extraction)results were $9.6 \pm 0.8 \%$ for $1: 20$ propolis/solvent $2 \times 10$ s was $9.3 \pm 0.1 \% ; 1: 10$ propolis/solvent $2 \times 10$ s was $8.7 \pm 0.1 \%$; $1: 10$ propolis/solvent $3 \times 10$ s was $10.7 \pm 1.7 \%$.

With regard to the Excel correlation, flavone and flavonol content had a positive correllation with flavanones and dihydroflavonols content.

To quantify flavanones and dihydroflavonols the DNP method was used. This is based upon the interaction of these compounds with DNP in acidic media to form coloured phenylhydrazones. The sum of the flavone and flavonol- flavanones and dihydroflavonols methods closely represents the real content of total flavonoids (Gomez-Caravaca et al. 2006).

The flavanones and dihydroflavonols content of the investigated samples were found between $6.58 \pm 0.0009$ and $12.94 \pm 0.007 \%$. The P5 sample showed the highest content and the P2 sample had the lowest content.

Popova et al. (2005) studied the flavanone and dihydroflavonol contents of some Turkish propolis. They found the values in the Yozgat sample was 6.0\%, Izmir 5.5\%, Kayseri 4.8\%, Adana 2.7\%, Erzurum 1.5\% and Artvin 3.0\%. With respect to our results these values are a bit lower.

In other research, Popova et al. (2007) found the flavanones and dihydroflavonols content minimum value $1.5 \%$, the maximum value $15.2 \%$ and the mean value $6 \%$ in poplar-type propolis samples. Furthermore, they researched six propolis samples (two from Bulgaria, Two from Italy and Two from Switzerland) and they found the Flavanones and dihydroflavonols values between 4.8 and $7.1 \mathrm{mg} / \mathrm{mL}$ (Popova et al. 2004). These results are similiar to our results.

Kalogeropoulos et al. (2009) analysed 12 propolis samples from Greece, the Greek islands and East Cyprus using GC-MS. They found compounds belonging to the alcohols, aliphatic acids, phenolic acids and esters, anthraquinones, flavonoids, sugars and terpenes groups. The hignest ratios were observed in flavonoids groups with a maximum value of $37.18 \%$.

Popova et al., (2005) carried out qualitative analysis of some Turkish propolis using GC-MS and found that the Adana sample contained diterpenic acids and a high amount of cinnamyl cinnamate, the Erzurum sample had expressive amounts of hydroxy fatty acids and triterpenic alcohols and the Artvin sample had phenolic glycerides, indicative of the Populus euphratica Oliv. bud exudates

Flavonoid compounds are more effective in the biological activities of propolis (Maciejewicz et al. 2001). Of the investigated samples, P5 had the highest flavonoid content (47.03\%). Acccording to the microscopic analysis results for the P5 sample, it was observed as a mixed type propolis. The P4 sample had a content of flavonoids with a ratio of $34.87 \%$ and was sourced mostly from plants belonging to the Brassicaceae family. The P3 sample had a 34.87 flavonoid content, that was mostly sourced from plants belong to the Brassicaceae family and Salix xpp.. The two chestnut propolis samples (P1 and P2) had lower flavonoid contents and total phenolic, flavone-flavonol and flavanones-dihydroflavonols contents.

Maciejewicz et al. (2001) investigated five propolis samples from Poland and identified pinostrobin chalcone, pinocembrin, tetrochrysin, chrysin, galangin, 5-Hydroxy-4',7-dimethoxyflavone, pilloin and apigenin using GC-MS.

According to the literature the most commonly identified flavonoids in different propolis samples from the various countries were pinocembrin, tetrochrysin, chrysin, and galangin. The occurence of pilloin in propolis was reported firstly by Maciejewicz et al., (2001). Similiar to previous research, we found chrysin, tetrochrysin, pinostrobin and chalcone in the investigated samples.

\section{CONCLUSION}

The results obtained in our work allow a preliminary pollen characterization of Turkish propolis and its correlation with the content of biologically active compounds. It is observed that the balsamic content has no positive correllation with total phenolic, flavone-flavonol and flavanones-dihydroflavonols contents, but total phenolic contents have a positive corellation with flavone and flavonol content, flavanones and dihydroflavonols contents.

Total phenolic and flavone-flavonol contents were found highest in the sample that sourced from the taxa belonging to the Brassicaceae family, this was contrary to common belief as the chesnut propolis has higher phenolic contents. 
Through this research, we determined the possible botanical sources, geographical origins and their influence on the chemical characterization of propolis samples. These results can be helpful for further research. To reach certain botanical sources and characterize propolis on a regional base, more samples are necesary for investigation.

Peer-review: Externally peer-reviewed.

Author Contributions: Concept - Ö.G.Ç.; Design - Ö.G.Ç.; Supervision - Ö.G.Ç., K.S., M.A.; Resource - Ö.G.Ç., K.S.; Materials - Ö.G.Ç.; Data Collection and/or Processing - Ö.G.Ç.

Acknowledgements: We would like to acknowledge supports from the Beekeepers for collecting samples.

Conflict of Interest: The authors have no conflict of interest to declare.

Financial Disclosure: The authors declared that this study has received no financial support.

\section{REFERENCES}

- $\quad$ Ahn MR, Kumazawa S, Usui Y, Nakamura M, Matsuka M, Zhu F, NakayamaT (2007). Antioxidant activity and constituents of propolis collected in various areas of China. Food Chem 101: 1383-1392. [CrossRef]

- $\quad$ Barth OM (1998). Pollen analysis of Brazilian propolis. Grana 37: 97-101. [CrossRef]

- Bonvehi JS, Coll FV, Jorda RE (1994). The composition, active components and bacteriostatic activity of propolis in dietetics. $J$ American Oil Chemists' Society 71: 529-532. [CrossRef]

- Burdock GA (1998). Review of the Biologşcal Properties and Toxicity of Nee Propolis (propolis). Food Chem Toxicol 36: 347-363. [CrossRef]

- Chen CN, Weng MS, Wu CL, Lin JK (2004). Comparison of Radical Scavenging Activity, Cytotoxic Effects and Apoptosis Induction in Human Melanoma Cells by Taiwanese Propolis From Different Sources. Evid Based Complement Alternat Med 1: 175-185. [CrossRef]

- Choi YM, Noh DO, Cho SY, Suh HJ, K.m KM, Kim JM (2006). Antioxidant and antimicrobial activities of propolis from several regions of Korea. Food Sci Techno/ 39: 756-761. [CrossRef]

- Choi SJ, Shimomura K, Kumazawa S, Ahn MR (2013). Antioxidant properties and phenolic composition of propolis from diverse geographic regions in Korea. Food Sci Technol Res 19: 211-222. [CrossRef]

- Cottica SM, Sawaya ACHHF, Eberlin MN, Franco SLF, Zeoula LM, Visentainer JV (2011). Antioxidant activity and Composition of propolis obtained by different method of extraction. J Braz Chem Soc 22: 929-935. [CrossRef]

- Cunha IBS, Sawaya ACHF, Caetano FB, Shimizu MT, Marcucci MC, Drezza FT, Povia GS, Carvalho PO (2004). Factors that influence the yield and composition of Brazilian Propolis Extracts. J Braz Chem Soc 15: 964-970. [CrossRef]

- Çelemli ÖG, Sorkun K (2012). The plant choices of Honey Bees to Collect Propolis İ Tekirdağ-Turkey. Hacettepe J Biol Chem 40: 45-51.

- Daleprane JB, Abdalla D S (2013). Emerging Roles of Propolis: Antioxidant, Cardioprotective, and Antiangiogenic Actions. Evid Based Complement Alternat Med doi: 10.1155/2013/175135. E. [CrossRef]

- Gençay, Ö (2004). Identification of Botanical Origin and Chemical Composition of Propolis From Kemaliye-Erzincan Region. Master Thesis.

- $\quad$ Gençay Ö, Salih B (2008). GC-MS Analysis of Propolis Samples From Different Regions of Turkey, Four Different Regions of Brazil and One From Japan. Mellifera 9: 19-28.
Ghisalberti EL (1979). Propolis: a review. Bee World 60: 59-84. [CrossRef] Gómez-Caravaca AM, Gómez-Romero M, Arráez-Román D, Segura-Carretero A, Fernández-Gutiérrez A (2006). Advances in the analysis of phenolic compounds in products derived from bees. J Pharm Biomed Anal 41: 1220-1234. [CrossRef]

- Gülçin I, Bursal E, Şehitoğlu MH, Bilsel M, Gören AC (2010). Polyphenol contents and antioxidant activity of lyophilized extract of propolis from Erzurum, Turkey. Food Chem Toxicol 48: 22272238. [CrossRef]

Jun X (2006). Comparison of Antioxidant activity of Ethanolic Extracts of Propolis Obtained By Different Extraction Methods. Can J Chem Eng 84: 447-451. [CrossRef]

Kalogeropoulos N, Konteles SJ, TRoullidou E, Mourtzinos I, Karathanos V (2009). Chemical composition, antioxidant activity and antimicrobial properties of propolis extracts from Greece and Cyprus. Food Chem 116: 452-461. [CrossRef]

Kumazawa S, Hasmasaka T, Nakayama T (2004). Antioxidant activity of propolis of various geographic origins. Food Chem 84: 329-339. [CrossRef]

- Maciejewicz W, Daniewski M, Markowski W (2001). GC-MS Identification of the Flavonoid Aglycones Isolated from Propolis. Chromatographia 53: 343-346. [CrossRef]

- Marcucci MC (1995). Propolis : chemical composition, biological properties and therapeutic activity. Apidologie 26: 83-99. [CrossRef] Mohammadzadeh S, Sharriatpanahi M, Hamedi M, Amanzadeh Y, Ebrahimi SES, Ostad SN (2007). Antioxidant power of Iranian propolis extract. Food Chem 103: 729-733. [CrossRef]

Moreira L, Dias LG, Pereira JA, Estevinho L (2008). Antioxidant properties, total phenols and pollen analysis of propolis samples from Portugal. Food Chem Toxicol 46: 3482-3485. [CrossRef]

- Popova M., Bankova V Butovska D, Petkov V, Nikolova-Damyanova B, Sabatini AG, Marcazzan GL, Bogdanov S (2004). Validated Methods for the Quantification of Biologically Active Constituents of Poplartype Propolis. Phytochemical Analysis 15: 235-240. [CrossRef]

- Popova M, Silici S, Kaftanoğlu O, Bankova V (2005). Antibacterial activity of Turkish propolis and its qualitative and quantitative chemical composition. Phytomedicine 12: 221-228. [CrossRef]

- Popova MP, Bankova VS, Bogdanov S, Tsvetkova I, Naydenski C, Marcazzan GL, Sabatini AG (2007). Chemical characteristics of poplar type propolis of different geographic origin. Apidologie 38: 306-311. [CrossRef]

- Sarıaya AO, Ulusoy E, Öztğrk N, Tunçel M, Kolaylı S (2009). Antioxidant Activity and Phenolic Acid Constituents of Chesnut (Castanea Sativa Mill.) Honey and Propolis. J Food Biochem 33: 470-481. [CrossRef] Silva JFM, Souza MC, Matta SR, Andrade MR, Vidal FVN (2006). Correlation analysis between phenolic levels of Brazilian propolis extracts and their antimicrobial and antioxidant activities. Food Chemistry 99: 431-435. [CrossRef]

Trusheva B., Trunkova D, Bankova V (2007). Different extraction methods of biologically act ive components from propolis: a preliminary study. Chemisrty Central Journal 1: 13. [CrossRef]

- Valencia D, Alday E, Zepeda RR, Escobar A, Ruiz JC, Reyes M, Estrada M, Conteras E, Hermandez J, Velazquez C (2012). Seasonal effect on chemical composition and biological activities of Sonoran propolis. Food Chemistry 131: 645-651. [CrossRef]

Warakomska Z, Maciejewicz (1992). Microscopic analysis of propolis from Polish regions. Apidologie 23: 277-283. [CrossRef] Woisky RC, Salatino A (1998). Analysis of propolis: some parameters and procedures for chemical quality control. J Apicult Res 37: 99-105. [CrossRef]

Yaghoubi SMJ, Ghorbani GR, Soleimanian ZS, Satari R (2007). Antimicrobial activity of Iranian propolis and its chemical composition. DARU 15: 1 . 